Review Article

\title{
Recent Advances on Pathophysiology, Diagnostic and Therapeutic Insights in Cardiac Dysfunction Induced by Antineoplastic Drugs
}

\author{
Marilisa Molinaro, ${ }^{1}$ Pietro Ameri, ${ }^{2}$ Giancarlo Marone, ${ }^{3}$ Mario Petretta, ${ }^{4}$ Pasquale Abete, ${ }^{4}$ \\ Fabio Di Lisa, ${ }^{5,6}$ Sabino De Placido, ${ }^{3}$ Domenico Bonaduce, ${ }^{4}$ and Carlo G. Tocchetti ${ }^{4}$ \\ ${ }^{1}$ Department of Medicine and Health Sciences, University of Molise, 86100 Campobasso, Italy \\ ${ }^{2}$ Department of Internal Medicine, University of Genova, 16132 Genova, Italy \\ ${ }^{3}$ Department of Clinical Medicine and Surgery, Federico II University, 80131 Naples, Italy \\ ${ }^{4}$ Department of Translational Medical Sciences, Division of Internal Medicine, Federico II University, 80131 Naples, Italy \\ ${ }^{5}$ Department of Biomedical Sciences, University of Padova, 35121 Padova, Italy \\ ${ }^{6}$ National Researches Council, Neuroscience Institute, University of Padova, 35121 Padova, Italy
}

Correspondence should be addressed to Carlo G. Tocchetti; carlogabriele.tocchetti@unina.it

Received 13 April 2015; Accepted 1 July 2015

Academic Editor: Giulio Agnetti

Copyright (C) 2015 Marilisa Molinaro et al. This is an open access article distributed under the Creative Commons Attribution License, which permits unrestricted use, distribution, and reproduction in any medium, provided the original work is properly cited.

\begin{abstract}
Along with the improvement of survival after cancer, cardiotoxicity due to antineoplastic treatments has emerged as a clinically relevant problem. Potential cardiovascular toxicities due to anticancer agents include QT prolongation and arrhythmias, myocardial ischemia and infarction, hypertension and/or thromboembolism, left ventricular (LV) dysfunction, and heart failure (HF). The latter is variable in severity, may be reversible or irreversible, and can occur soon after or as a delayed consequence of anticancer treatments. In the last decade recent advances have emerged in clinical and pathophysiological aspects of LV dysfunction induced by the most widely used anticancer drugs. In particular, early, sensitive markers of cardiac dysfunction that can predict this form of cardiomyopathy before ejection fraction (EF) is reduced are becoming increasingly important, along with novel therapeutic and cardioprotective strategies, in the attempt of protecting cardiooncologic patients from the development of congestive heart failure.
\end{abstract}

\section{Introduction}

The prognosis of cancer has dramatically improved in the last decades: several types of malignancies can be now cured or maintained in remission for a long time and patients can live the remainder of their lives free of disease. However, they are also exposed to chronic complications of antineoplastic treatments. Many classes of chemotherapeutic drugs can impair cardiovascular homeostasis and favor or even trigger cardiovascular disorders. The more the survival of oncological patients increases, the higher is the likelihood that cardiovascular consequences of cancer therapies become the major health problem after tumor elimination is achieved. The most common side effects of anticancer treatment include vasospastic and thromboembolic ischemia, arterial hypertension, arrhythmia, and cardiac dysfunction up to heart failure (HF) $[1,2]$. The latter is an especially fearful long-term complication of chemotherapy because it remains a slowly progressing condition that ultimately can only be resolved by heart transplantation. Nevertheless, this procedure can be offered only to a small percentage of subjects due to the limited availability of donor organs. In fact, the number of heart transplants has remained static worldwide and the number of heart transplants performed each year in the United States has plateaued at about 2100 for the past few years (2001 Heart and stroke statistical update. Dallas: American Heart Association, 2000).

Here we first give an updated overview of the main characteristics and mechanisms of chemotherapy-associated cardiac toxicity, since a thorough knowledge of this 
phenomenon can provide important hints to predict, treat, and prevent it. Special attention is paid for chemotherapyrelated cardiac dysfunction, in the light of the clinical and social burden of heart failure that may ensue $[3,4]$. Next, we examine the approaches that have already been implemented in clinical practice or are currently being investigated for the prompt diagnosis and effective management of chemotherapy cardiotoxicity.

\section{Classification of Chemotherapy-Related Cardiotoxicity}

Left ventricular (LV) dysfunction induced by anthracyclines has historically been the most relevant form of chemotherapy cardiotoxicity [7]. Nevertheless, new oncological drugs, such as intracellular signaling inhibitors, may be also cardiotoxic, as they target pathways that also play a major role in the maintenance of cardiac homeostasis, especially when during stressful conditions, such as hypertension or hypertrophy [1]. For instance, human epidermal growth factor receptor 2 (HER/ErbB2) and angiogenesis inhibitors, which have entered clinical practice in relatively recent years, profoundly affect cardiac metabolism and contractile proteins (for important reviews on such mechanisms, please refer to [2, 8-12]). This type of toxicity does not display cardiomyocyte disruption, is most often reversible with treatment discontinuation, and has been named type II LV dysfunction [13]. Conversely, cardiotoxicity produced by anthracyclines is typically irreversible, with marked ultrastructural myocardial derangements, and is referred to as type I [13]. However, these two paradigms of cardiotoxicity may overlap: for example, the anti-ErbB2 antibody, trastuzumab, can trigger irreversible cardiac damage in patients previously treated with anthracyclines [14].

\section{Cardiotoxicity of Anthracyclines}

Anthracyclines are antibiotics belonging to the family of rodomicine, originally isolated from Streptomyces peucetius, with very potent antineoplastic activity [15]. In particular, doxorubicin and epirubicin are currently the cornerstone of treatment of many malignancies, including breast cancer, lymphomas, and sarcomas. It has been estimated that approximately $10 \%$ of patients receiving doxorubicin or its derivatives will develop cardiac complications, even up to 10 years after the completion of chemotherapy [1]. However, endomyocardial biopsy studies and seriate measurements of troponin I have revealed that cardiac cell alterations already occur during or a few hours after exposure to anthracyclines, regardless of when clinical manifestations appear. Furthermore, an early and subclinical deterioration of systolic function can be detected in most patients exposed to anthracyclines with Tissue Doppler or Speckle Tracking echocardiography $[16,17]$. The delay between cardiac injury and clinical presentation may be explained by the fact that anthracycline cardiotoxicity is temporarily compensated for by the activation of protective signaling pathways and by a myocardial functional reserve $[18,19]$.
The probability of developing anthracycline cardiomyopathy is primarily dose dependent [20]. Additional risk factors are genetic predisposition, very young or old age, female gender, intravenous bolus infusion, hypertension, diabetes mellitus, preexisting cardiac disease, previous or concurrent mediastinal radiation therapy, and combination with alkylating or antimicrotubule chemotherapeutics $[1,21-$ 26]. Thus, accurate medical history may be helpful in identifying individuals susceptible to anthracycline cardiotoxicity. However, it should be noted that many of the aforementioned risk factors have been identified over relatively short followup periods and that long-term investigations are needed to confirm their relevance [1].

3.1. Molecular Mechanisms of Anthracycline Cardiotoxicity. Anthracyclines are DNA intercalating agents that form a ternary complex with topoisomerase 2 . This enzyme transiently breaks the DNA backbone to untangle the supercoiled DNA complex in a process required for transcription, replication, and recombination [2, 27, 28]. Under physiological conditions topoisomerase 2 reanneals the cut strands. Conversely, when the complex with anthracyclines is formed, the relegation is inhibited resulting in an uncontrolled occurrence of DNA strand breaks. The resulting cascade of molecular events, referred to as DNA damage response, eventually leads to mitochondrial dysfunction and accumulation of reactive oxygen species (Figure 1) [27]. Consistent with this model, doxorubicin cardiotoxicity is prevented in mice knockout for the gene encoding the cardiac isoform of topoisomerase 2 [27]. Besides eliciting the DNA damage response, anthracyclines also cause the formation of reactive oxygen species by accepting and immediately releasing electrons onto the oxygen molecules present inside the cardiomyocyte, especially in mitochondria [15, 27-31]. Furthermore, anthracyclines induce the intracellular accumulation of iron and form complexes with it, further inducing the production of free oxygen radicals via metalcatalyzed oxidoreductions [15, 29-31]. The DNA damage response and oxidative stress initiate a number of secondary cellular alterations, such as changes in calcium homeostasis and abnormalities of the contractile apparatus [15, 29-31]. At the ultrastructural level loss of myofibrils, dilation of the sarcoplasmic reticulum and cytoplasmic vacuolization are observed [15, 29-31]. Eventually, cardiomyocytes may die or undergo senescence following exposure to anthracyclines [32]. This can be because of direct toxicity of anthracyclines or as a result of the impairment of antiapoptotic signaling axis. For instance, our recent work has pinpointed a state of resistance to insulin-like growth factor-1, a hormone fundamental for cardiomyocyte survival, as a mechanism of doxorubicin-triggered death of cardiac cells [33, 34]. It has been proposed that apoptosis and senescence of cardiac progenitor cells chiefly contribute to the pathogenesis of anthracycline cardiomyopathy, as depletion of these cell population hinders the ability of the heart to regenerate in response to minor injuries which, thereby, accumulate and affect cardiac structure and function $[35,36]$.

Moreover, it is conceivable that anthracyclines also alter the activity of cardiac fibroblasts and the turnover of the 
myocardial extracellular matrix. Doxorubicin enhances the expression of MMP2 and MMP9, thus weakening the collagenous matrix and contributing to myocardial remodeling $[15,37,38]$. Indeed, fibrosis is observed in hearts that have been exposed to doxorubicin [36] and may impinge on both diastolic and - via misalignment of cardiomyocytes - systolic function.

Anthracyclines also induce a local immune response, with the involvement of dendritic cells and distinct subsets of T lymphocytes, which may underlie part of the antineoplastic effect [39]. However, immune activation and inflammation may be harmful to the heart. Since anthracycline-triggered inflammation is at least in part secondary to the activity of IL- $1 \beta$, suppression of the latter might blunt some of the adverse inflammatory effects that complicate chemotherapy with anthracyclines [40].

3.2. Other Agents. Mitoxantrone is an anthracycline analog that can damage myocytes, resulting in LV dysfunction similarly to anthracycline $[1,41]$. Large single doses of cylophosphamide are able to cause hemorrhagic cell necrosis, bringing to heart failure or even death. Such toxic effects are seen very rarely since lower doses are being used these days $[1,42]$. Another drug that has been linked to late-onset LV dysfunction (milder than anthracyclines) is cisplatin $[1,43]$.

Also, taxanes such as paclitaxel and docetaxel are antimicrotubule agents that bind to tubulin, thus impairing the disassembly of microtubules and inhibiting cell division. They are widely used in the treatment of multiple malignancies. The incidence of HF associated with such drugs, according to retrospective analysis, is relatively low (1.6\% among patients treated with docetaxel-doxorubicin-cyclophosphamide and $0.7 \%$ for those treated with 5-fluorouracil-doxorubicincyclophosphamide) [44, 45].

The antimetabolite 5-fluorouracil (5-FU) has been shown to cause angina-like chest pain and, in rare cases, myocardial infarction, arrhythmias, LV dysfunction, and sudden death [46-48]. In animal models, direct toxicity on the myocardium has been postulated. This could be due to myocardial accumulation of citrate that has been attributed to generation of fluoroacetate (formed from the degradation of 5-FU parenteral preparation) and can interfere with the Krebs cycle [48-51]. Also 5-FU can induce dose- and timedependent depletion of high energy phosphates, apoptosis $[48,51-53]$, autophagy, ROS elevation, and senescence of cardiomyocytes and endothelial cells [54].

\section{Cardiotoxicity of Type II Agents}

4.1. Anti-ErbB2 Agents. The first and most widely used type II cardiotoxic drug is trastuzumab, a humanized monoclonal antibody against the extracellular domain IV of HER/ErbB2 $[8,9]$.

ErbB2 (also called HER2) is a member of the epidermal growth factor receptor family. Upon ligand binding, these transmembrane receptors homo- or heterodimerize, undergo transphosphorylation, and initiate a number of cellular responses. As no specific ligand for ErbB2 has been identified so far, it is believed that it normally functions as a dimerization partner of the other ErbBs [9]. By contrast, ErbB2 is overexpressed in about $30 \%$ of breast cancers, in which it spontaneously interacts with the other ErbBs independent of ligand stimulation, and triggers signaling cascade promoting tumor growth and survival [55]. Trastuzumab is highly effective in treating ErbB2-positive breast and also gastric cancers. However, it also causes cardiac dysfunction in a substantial proportion of patients, which was found to peak to $28 \%$ when trastuzumab is coadministered with anthracyclines [56, 57]. In fact, this association is now avoided.

As a class II cardiac dysfunction [58], trastuzumabinduced cardiac dysfunction appears to arise from impairment of contractility rather than loss of myocytes, and the release of troponin shown in sequential treatment with anthracyclines + trastuzumab seems to be ascribed to the previous chemotherapy [59]. EF is likely to recover and there is evidence that it is relatively safe to readminister trastuzumab after it has been discontinued and myocardial function has returned to baseline [13].

Pertuzumab is another, more recent anti-HER2 antibody that binds to the domain II of the receptor. A third HER2targeting agent is lapatinib, a small molecule inhibitor of the intracellular tyrosine kinase domain of HER2. Trastuzumab only disrupts ligand-independent HER2 signaling; conversely, pertuzumab interferes with the formation of ligandinduced HER2 heterodimers. Lapatinib affects both ligandtriggered and ligand-independent HER2 signaling [9]. Interestingly, lapatinib seems to be less toxic than trastuzumab. Data about the toxicity of pertuzumab are limited [57].

Cardiotoxicity of HER2-targeting drugs has been ascribed to the inhibition of fundamental actions of neuregulin- 1 in the heart $[57,60]$. Neuregulin-1 acts on cardiac cells via ErbB4/ErbB4 homodimers and ErbB4/ErbB2 heterodimers to elicit protective pathways in response to stress (Figure 1) [60]. By blocking neuregulin-1 effects in the heart, HER2 inhibitors may make it more vulnerable to noxious stimuli, among which anthracyclines. Consistent with this interpretation, mice with cardiac-specific deletion of ErbB2 show dilated cardiomyopathy, with increased susceptibility to cardiomyocyte death after anthracyclines [61]. The ErbB2 pathway is required for cell survival and continuing function and seems to be activated when the myocardium faces adverse hemodynamics or other stress, such as anthracycline therapies [62]. Upon withdrawal of trastuzumab, the normal ErbB2 pathway is reestablished, and the declined EF can return to normal, opposite to anthracyclines that produce a type I toxicity with permanent myocyte dysfunction. This is consistent with the increase in cardiotoxicity when trastuzumab is associated with anthracyclines: trastuzumab enhances or even uncovers the damage caused by anthracyclines. Once ErbB2 inhibitors block the ErbB2triggered repair mechanisms, the oxidative damage induced by anthracyclines proceeds without control [59]. Indeed, experimental studies have shown that neuregulin 1 modulates doxorubicin damage in rat cardiomyocytes [14, 57, 63, 64]. 


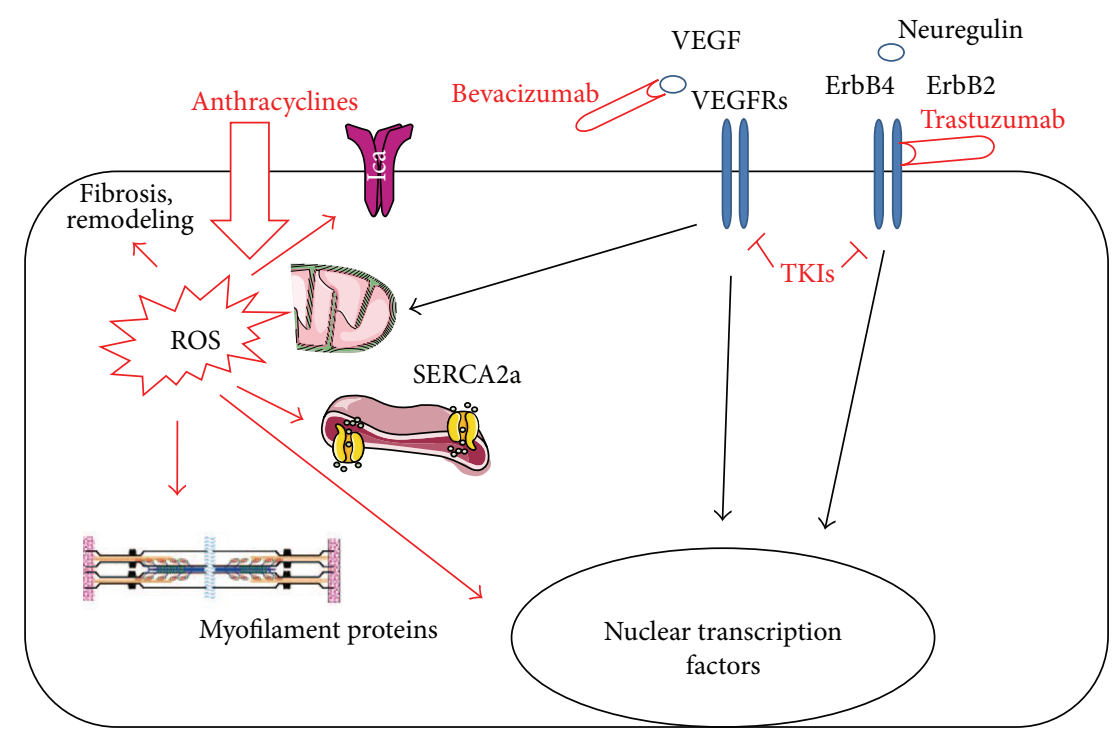

FIGURE 1: Schematic representation of the main mechanisms by which cardiomyocytes are damaged by the most cardiotoxic anticancer agents among those currently in use. Anthracyclines induce a DNA damage response and reactive oxygen species (ROS) production; these two initial events result in a cascade of secondary alterations affecting mitochondrial integrity and function, intracellular calcium dynamics, and contractile proteins. By blocking the activity of tyrosine kinase receptors, such as vascular endothelial growth factor receptor (VEGFR) or ErbB2/ErbB4, bevacizumab, trastuzumab, and tyrosine kinase inhibitors (TKIs) alter mitochondria and modulate gene expression. SERCA2a: sarcoendoplasmic reticulum calcium ATPase. Black arrows indicate physiologic, homeostatic effects. Red arrows indicate deleterious effects. Modified from $[5,6]$.

With its cardioprotective features, neuregulin is now being intensively studied in clinical trials as a therapeutic for heart failure [65].

4.2. Antiangiogenic Drugs. Among drugs that induce type II cardiotoxicity we have to acknowledge antiangiogenic drugs. In particular, bevacizumab, sorafenib, and sunitinib are now widely used in oncology; more recently, pazopanib and vandetanib have also been approved by the US Food and Drug Administration [1, 66, 67]. All these drugs interfere with vascular endothelial growth factor (VEGF) signaling (Figure 1). As VEGF contributes to cardiomyocyte function and growth on the one hand and to the integrity and expansion of the coronary and systemic circulation on the other one $[8,10,11,45,67-70]$, it is not surprising that VEGF antagonism may lead to cardiovascular side effects, principally hypertension, thromboembolism, LV dysfunction, and HF [71-73]. Indeed, like cancer, the heart is highly dependent on adequate perfusion for its normal function $[8,10,11,45,67-70]$, both relying on similar HIF-1 and VEGF pathways. Indeed, the inhibition of HIF-1 by p53 causes cardiac dysfunction during chronic pressure overload [74], and conditional expression of a VEGF scavenger caused microvessel rarefaction and myocardial hibernation which was fully reversible even months after switching off the expression of the scavenger $[75,76]$. These data suggest that the heart is especially sensitive to antiangiogenic therapies in the setting of hypertension-related pressure overload.

Bevacizumab is an antibody, which binds specifically to circulating VEGF-A (that activates signaling in endothelial cells), and is currently approved for the treatment of advanced carcinoma of the lung, breast, and colon-rectum [77, 78]. Bevacizumab has been reported to induce LV dysfunction in $1 \%$ of chemotherapy-naïve patients and $3 \%$ of patients who have already received chemotherapy [79]. Instead, sunitinib and sorafenib, which are used in metastatic renal cancer and in imatinib-resistant gastrointestinal stromal tumors $[72,80]$, belong to the class of small molecule tyrosine kinase inhibitors. They are not very selective and also block signaling cascades other than the one of VEGF [10]. In particular, sunitinib inhibits more than 30 other receptor and nonreceptor tyrosine kinases, including $\mathrm{c}$-Kit, plateletderived growth factor receptor (PDGFR) alpha and beta, rearranged during transfection (RET), FMS-related tyrosine kinase 3 (FLT3), and colony-stimulating factor 1 receptor (CSF1R) $[8,10,39,81]$, which may be why it appears to be more cardiotoxic than other angiogenesis inhibitors, with a reported decrease in EF in up to $28 \%$ of treated patients [8285]. Seminal studies [86-90] have proven the importance of these pathways in cardiovascular homeostasis. The higher incidence of sunitinib cardiotoxicity is also explained by inhibition of off-target kinases, such as ribosomal S6 kinase (RSK), with consequent activation of the intrinsic apoptotic pathway, and $5^{\prime}$ AMP-activated protein kinase (AMPK, important for the response to energy stress), with worsening of ATP depletion $[8,91]$. Therefore, LV dysfunction would occur due to myocyte dysfunction. In mice treated with sunitinib and exposed to pressure load, Chu and colleagues [82] observed that cardiomyocytes exhibited opening of the mitochondrial permeability transition pore and marked mitochondrial swelling with destruction of the normal mitochondrial architecture. Moreover, direct administration of 
sunitinib on different myocardial preparations results in a dose-dependent inotropic effect, accompanied by decline in intracellular $\mathrm{Ca}^{2+}$ and increased reactive oxygen species (ROS) production [67, 92].

At clinically relevant concentrations in in vitro kinase assay, sorafenib inhibits at least 15 kinases, including VEGF receptor, PDGFR, Raf-1/B-Raf, c-Kit, and FLT3 [8, 10, 67]. The rate of cardiotoxicity associated with sorafenib is not yet clear. Two meta-analysis, including almost 7000 patients treated with sunitinib and 900 patients treated with sorafenib, found a $4.1 \%$ rate of sunitinib-induced $\mathrm{HF}$ and $1 \%$ for sorafenib-associated cardiac dysfunction [93, 94], but most of these data are from retrospective analyses; only few trials have evaluated cardiac function and HF prospectively. Schmidinger and colleagues [71] reported that 3 out of 14 patients treated with sorafenib who experienced cardiac events showed abnormal EF.

Interestingly, a recent work from the Paolocci group [95] reported that a tyrosine kinase-receptor such as TrkB, with its endogenous ligand BDNF, is able to modulate the cardiac excitation-contraction coupling process directly, independently and in parallel to $\mathrm{G}$ protein-coupled receptor signaling. Such findings corroborate the concept that tyrosine kinase inhibition during anticancer therapies can disrupt important signaling, leading to consequent derangements in cardiac mechanical work that may largely contribute to loss in LV function [96].

Significant hypertension is seen with all three major antiangiogenic agents [97]. Bevacizumab results in a more serious form of hypertension that, at least in some instances, does not reverse with the removal of the offending agent. Remarkably, it has been suggested that drug-induced hypertension may be a biomarker of anticancer efficacy since patients who developed hypertension survived longer than those who did not [98]. In the work of Scartozzi and colleagues [99] on metastatic colorectal cancer patients, $20 \%$ of patients developed grade 2-3 hypertension. A partial remission was observed in $75 \%$ of patients with bevacizumabrelated hypertension and only in $32 \%$ of those without hypertension. Furthermore, patients who developed grade 2-3 hypertension had significantly longer progression-free survival than nonhypertensive patients [99].

4.3. Other Type 2 Agents. The BCR-ABL inhibitors, imatinib and dasatinib, are tyrosine kinase inhibitors used for treatment of chronic myelogenous leukemia and gastrointestinal stromal tumors. These two drugs were initially reported to induce HF, but large follow-up studies did not confirm such data $[1,100,101]$.

\section{Assessment and Treatment of Cardiac Damage during Cancer Treatment}

Assessment of anticancer drug-related cardiotoxicity is an essential procedure before, during, and after treatment with these drugs. The majority of currently used methods used to assess cardiac function cannot differentiate between irreversible and reversible cardiotoxicity and may mislead physicians to stop potentially lifesaving cancer therapies. Cardiovascular side effects such as myocardial ischaemia, arterial hypertension, and dysrhythmia can be readily diagnosed, but detection of cardiac dysfunction is more challenging [1].

Preclinical screening for cardiotoxicity is fundamental for kinase inhibitors. Much preclinical screening focuses on the hERG ( $\mathrm{K}^{+}$channel) assay because many drugs increase risk of arrhythmia. Primary cell cultures of human cardiomyocytes dedifferentiate and die quickly over time; therefore, they are not a good reflection of what happens in vivo. In the future, stem-cell-based assays and assays based on the use of engineered heart tissue could be used. These assays could integrate effects on membrane action potential, calcium handling, myofilament function, gene expression, and cell survival $[1,8,9,11,66,67,103]$.

For initial screening and detection of cardiac dysfunction in oncologic patients, along with ECG and physical assessment, noninvasive imaging with echocardiography or MUGA (Multiple Gated Acquisition) scans are now commonly used in cancer patients $[1,45,57,104,105]$. These methods are useful for evaluating patients for cardiotoxicity but have limited accuracy for risk stratification [1]. Attention should be paid not only to systolic but also to diastolic cardiac function. It should be noted that patients with advanced cancer may already have cardiovascular abnormalities such as fatigue, dyspnea, malaise, and propensity to severe arrhythmia. Distinguishing these from side effects attributable to cancer therapies requires a specific expertise.

One important and very active field of research is the search of new indexes of cardiac function other than the ejection fraction $[106,107]$. Although strong outcomes data support MUGA for estimation of LVEF, such methodology is limited by radiation exposure. On the other hand, echocardiographic EF measurement is to be preferred for its simplicity and availability, but has the downside of being variable and insensitive [108]. Indeed, the normal heart has a huge recruitable contractile potential; therefore it must have undergone a considerable damage and myocyte loss in order for EF to be decreased [109]. On such basis, it is important to use other markers for cardiac function in the diagnostic armamentarium [57, 59, 105, 109-116]. More sensitive techniques to be used in the cardiotoxicity settings could be contrast that increases border definitions, enhancing accuracy and limiting interobserver variability [117-119], while echo-stress could evidence undiagnosed functional changes [119-121]. Tissue Doppler and strain techniques have been shown to detect anthracycline-induced cardiac dysfunction earlier than conventional echocardiography, but it is not known if these methods have a higher specificity to detect type I cardiotoxicity [122]. Instead, other superior imaging methodologies such as cardiac magnetic resonance (CMR) look promising (Table 1). A downside of this methodology is its limited availability, but it can provide improved accuracy and reproducibility of EF measurements [108]. Also, it has the unique property of characterizing the myocardial tissue, identifying myocardial inflammation, edema, and strain [119]. Other explored modalities include the use of the uptake of iodine-123-metaiodobenzylguanidine (MIBG), a radiolabeled analogue of norepinephrine, which decreases 
TABLE 1: Current insights in prevention, monitoring and treatment of cardiac dysfunction induced by anticancer drugs. Modified from [102].

\begin{tabular}{lll}
\hline Prevention & Monitoring & Treatment \\
\hline $\begin{array}{l}\text { Alternative anticancer strategies } \\
\text { Reduced chemotherapeutic dose }\end{array}$ & & \\
Liposomal formulations & & \\
Less toxic alternatives (epirubicin, lapatinib) & Imaging & \\
Better patients selection & Assess the best modality & \\
Age & Assess the best frequency & Hold or stop antineoplastic treatments \\
Cardiac risk & Biomarkers & Start HF therapies \\
Cardiac function & BNP & \\
Use of cardioprotective drugs & Troponins & \\
$\beta$-blockers & Novel markers (MPO?) & \\
ACE inhibitors & & \\
ARBs & & \\
Dexrazoxane & & \\
Statins & & \\
\hline
\end{tabular}

following cardiac damage $[119,123,124]$. Additionally, actomyosin antibodies could be used to detect myosin exposed after myocardial injury $[119,125,126]$. Finally, a predictor of cardiotoxicity may also be the uptake of radiolabeled chemotherapeutics $[119,127,128]$.

The use of cardiac biomarkers (Table 1) can solve the limitations of cardiac imaging to stratify the risk in cancer patients with cardiac dysfunction. Cardiac biomarkers such as troponins and natriuretic peptides may be expected to be elevated with significant cardiotoxicity. Patients treated with anthracyclines showed a transient increase in brain natriuretic peptide (BNP), but the predictive value for longterm cardiotoxicity may be limited when such marker is used alone $[129,130]$. Instead, troponins I and T have been shown to predict late anthracycline cardiotoxicity in children [131], and in an adult population they can identify anthracyclinestreated patients that can benefit from ACE-inhibitors [132]. In spite of these promising results, the assessment of cardiac biomarkers is not being performed routinely in patients undergoing cancer treatment, and multicentre trials to evaluate the role of biomarkers in this population are a need [1]. A 2014 study from Ky et al., while confirming TnI to be associated with LV dysfunction in patients with breast cancer undergoing sequential therapy with doxorubicin and trastuzumab, also showed that a marker of oxidative stress such as myeloperoxidase (MPO) could be mechanistically relevant to cardiotoxicity with cancer therapy [133].

All things said, there is no current established algorithm for preoncologic treatments evaluation and followup of patients during and after cancer therapies. Nevertheless, we need to avoid that patients who survive cancer today develop cardiac dysfunction tomorrow. Therefore such patients should be strictly monitored by both cardiologists and oncologists [134]. In patients with indication for anticancer therapies, a first step would be to evaluate the cardiovascular risk (Table 1). This should be done on the basis of the identification of concomitant cardiovascular diseases and potential cardiovascular complications before anticancer treatments are started, keeping in mind that preexisting hypertension and heart diseases are common in oncologic patients. All in all, clinicians need to recognize and treat cardiovascular risk factors (hypertension, diabetes, current and previous cardiovascular disease, subclinical organ damage previously documented by ECG or echocardiography or carotid ultrasound study, established or subclinical renal disease, age, smoking, dyslipidemia, family history of premature cardiovascular disease, and abdominal obesity) in order to allow long-term continuous therapy with anticancer drugs $[1,45,57,67]$. Age is indeed an important factor, with elderly patients being at higher risk of both type 1 and type 2 cardiotoxicity [1]. Interestingly, anthracyclines are used for cancer in children, too, and both elderly patients and children can develop LV dysfunction at lower cumulative doses $[1,22$, 23]. Indeed the Childhood Cancer Survivor Study showed that, 30 years after anthracyclines, $73 \%$ of pediatric cancer survivors would develop at least 1 chronic condition, while $42 \%$ would develop a serious life threatening condition or even die of a chronic condition $[48,135]$. Greater susceptibility to anthracycline cardiotoxicity has been associated also with female gender [26]. This may be due not only to differences in the pharmacokinetic of anthracyclines between the two sexes, but also because of protection conferred by androgens. Indeed, unpublished data from our laboratory show that testosterone reduces the toxicity of doxorubicin in cultured cardiomyocytes. Finally, it has to be acknowledged that, besides elderly and children, there is a certain risk of cardiotoxicity with occupational exposure to antineoplastic drugs in health care workers, through inhalation of vapors or skin contact with drops. This is particularly true for anthracyclines, while there is no clear evidence of 5-FU cytotoxicity, although there can be chest pain, aspecific ECG disorders, and induction of coronary disease [136].

A complete history and examination, with ECG and blood pressure measurement, are absolutely indicated. Careful monitoring and treatment of blood pressure throughout therapy with angiogenesis inhibitors is important $[66,103]$. In such patients, ACE inhibitors, angiotensin receptor blockers (ARBs), and beta-blockers are to be preferred, especially considering that they are effective in preventing HF (Table 1) [67]. The US National Cancer Institute has recently published recommendations to maintain patients' blood pressure at lower than 140/90 $\mathrm{mmHg}[66,103]$. 
In spite of the above-mentioned limitations about EF monitoring, Suter and coworkers have proposed an EF based algorithm $[1,137]$ (EF decreases by $15 \%$ points or $10 \%$ points to a value below 50) which is easy to follow and can be combined with troponins and BNP. On such basis, when LV dysfunction is detected, systolic function should be reevaluated after 3 weeks, and eventual standard HF treatments can be started $[1,45,57,67]$. If life expectancy is good, aggressive therapies with devices can also be considered $[1,138]$. The priority for oncologic patients is reintroduction of anticancer treatments, even if cardiac therapies are concomitantly administered. Therefore strict monitoring of cardiac function is necessary. At the end of cancer treatments, EF should be monitored to check for late cardiotoxicity 6 months after the conclusion of the therapeutic regimen, then yearly for 2-3 years, and then every 3-5 years for life [1].

\section{Novel Potential Perspectives in Prevention of LV Dysfunction Induced by Antineoplastic Drugs}

According to the 2013 Focused Update of the AHA HF Guidelines, in order to prevent the onset of $\mathrm{HF}$, patients on anticancer drugs should be considered as stage A HF patients [139]. This stage identifies patients at high risk of developing HF, but without structural heart disease or symptoms of HF yet. On such basis, patients on cardiotoxic agents should undergo noninvasive evaluation of LV function with imaging tests and biomarkers (Table 1). HF symptoms and signs should be monitored; cardiovascular risk factors should be addressed. Current strategies to prevent cardiotoxicity (Table 1) include regulation of infusion times to limit peak serum concentrations of anthracyclines, use of liposomal anthracyclines, use of chemotherapy regimens not containing anthracyclines, administering anthracyclines and trastuzumab sequentially rather than concurrently [44, $137,140,141]$, and implementing schemes of cardioprotection (Table 1) [102]. Although the use of preventive cardioprotective therapeutics has been proposed [142-144], most of the studies on HF induced by anticancer drugs have focused on early detection and attenuation or reversion of signs of LV dysfunction [102, 111, 145].

Until now, the vast majority of the studies on cardioprotection have been performed mostly on anthracyclines and, in the case of breast cancer, on anthracyclines + trastuzumab $[30,146]$ and have been proposing dexrazoxane [147], ACE inhibitors [148], and statins [149, 150] (Table 1). Interestingly, a recent study has evaluated the use of $\beta$ blockers (Table 1) to prevent anthracycline-induced cardiotoxicity. Concomitant $\beta$-blocker use may be cardioprotective in patients receiving trastuzumab, anthracyclines, or both [151]. Kalay and colleagues [152] observed that, in patients treated with carvedilol, LV ejection fraction and dimensions do not change with respect to control subject, while undergoing anthracycline chemotherapy. However several preclinical investigations suggest that all $\beta$-blockers may not be equally effective in preventing chemotherapyinduced cardiotoxicity [102]. Selectivity for $\beta$ receptors seems important for cardiac protection from chemotherapy. In animal models of doxorubicin-induced cardiomyopathy, $\beta 2$ receptor-deficient mice develop severe and lethal acute cardiotoxicity, and the additional deletion of $\beta 1$ receptors rescues this completely [153]. Thus, in animals exposed to anthracyclines, $\beta 1$ activation seems to be cardiotoxic, whereas $\beta 2$ activation is cardioprotective. These data suggest that $\beta 1$ selective antagonist, rather than nonselective $\beta$ blockers, may offer greater protection against anthracycline-induced cardiomyopathy. Molecular mechanisms of cardioprotection from $\beta 2$ receptors activation are activation of prosurvival kinases and decrease in the intracellular concentration of calcium, thus attenuating the mitochondrial dysfunction seen with anthracyclines [154].

Among $\beta$-blockers, carvedilol also has well-known antioxidant properties [155] and is able to protect cells against doxorubicin toxicity by reducing oxidative stress and apoptosis [156-158]. The same authors [159, 160] also showed the effects of ARBs in preventing oxidative stress and cardiotoxicity from anthracyclines. Nebivolol, a $\beta 1$ selective antagonist and $\beta 3$ agonist, has also been shown to reduce oxidative stress, decrease markers of myocardial injury, and improve LV function [161].

\section{Conclusions}

Cancer drugs currently in use and novel agents that target signaling pathways may all cause problems for the heart. Therefore, to prevent the development of heart failure, it is important that oncologic patients are strictly monitored from cardiologists. Indeed, a fundamental component of cardiooncologic strategies is to establish the vital balance of accepting temporary cardiovascular side effects so as not to impede a patient's ability to benefit from cancer treatment. In a patient with metastatic disease, risk of cardiotoxicity becomes a minor concern; instead, in a patient with a good prognosis, the risk of cardiotoxicity becomes more important $[1,57,134]$. Knowledge of the cardiac effects of anticancer agents balanced with knowledge regarding the natural history of the malignancy and the likelihood of tumor response offers such patients the greatest chance for long-term disease-free survival [1].

In the first place, it is important to recognize patients who are at increased risk for developing cardiac dysfunction associated with cancer treatments. The major mechanisms of left ventricular dysfunction are based on the development of oxidative stress $[15,27-31]$ and inhibition of cell signaling pathways, by new treatment modalities such as kinase inhibitors, that may also be important for the survival and homeostasis of cardiovascular tissue (Figure 1) [8, 10, 11, 67]. Through observation of side effects caused by new anticancer agents, some cardiovascular signaling pathways have become more clearly understood. Indeed, it is important to understand the relevance of such pathways in order to treat heart failure patients and improve longevity and quality of life for cancer patients. Currently, about $20 \%$ of all the investments on drug development is dedicated to small molecule kinase inhibitors, the majority of which (about $80 \%$ ) being in cancer (with little component in inflammatory 
and other diseases) [10]. This class is second only to research on drugs targeting G-protein-coupled receptors. Based on the number of kinase inhibitors currently in phase 1 or later clinical trials (about 150 [162]) there appears to be no slowing down in drug development in this area [10]. Beside the fact that this field of research is particularly lucrative, this means that in the next years we are likely going to see a huge increase in the market in the number of compounds which will produce more cardiac dysfunction [10]. In parallel to such increase in drug development, an extremely active field of research is the pursuit of novel strategies to face cardiotoxicity employing new therapeutic approaches or genetic manipulation, miRNAs, and gene transfer $[4,163-$ 172].

\section{Conflict of Interests}

The authors declare that there is no conflict of interests regarding the publication of this paper.

\section{Authors' Contribution}

Marilisa Molinaro and Pietro Ameri share first authorship.

\section{Acknowledgments}

The authors dedicate their work to the memory of their collaborator Professor Guido Tarone, Ph.D., University of Torino, Italy, who prematurely passed away during the revision of this paper. Guido was a brilliant scientist and an exquisite friend; he was dedicating his scientific experience to cardiooncological signaling and had been just funded by AIRC, IG 2014, ID 15970. They will miss him terribly.

\section{References}

[1] T. M. Suter and M. S. Ewer, "Cancer drugs and the heart: importance and management," European Heart Journal, vol. 34, no. 15, pp. 1102-1111, 2013.

[2] B. Ky, P. Vejpongsa, E. T. H. Yeh, T. Force, and J. J. Moslehi, "Emerging paradigms in cardiomyopathies associated with cancer therapies," Circulation Research, vol. 113, no. 6, pp. 754764, 2013.

[3] S. J. Greene, G. C. Fonarow, M. Vaduganathan, S. S. Khan, J. Butler, and M. Gheorghiade, "The vulnerable phase after hospitalization for heart failure," Nature Reviews Cardiology, vol. 12, no. 4, pp. 220-229, 2015.

[4] E. Braunwald, "The war against heart failure: the Lancet lecture," The Lancet, vol. 385, no. 9970, pp. 812-824, 2015.

[5] C. G. Tocchetti, M. Molinaro, T. Angelone et al., "Nitrosoredox balance and modulation of basal myocardial function: an update from the italian society of cardiovascular research (SIRC)," Current Cancer Drug Targets. In Press.

[6] C. Zuppinger and T. M. Suter, "Cancer therapy-associated cardiotoxicity and signaling in the myocardium," Journal of Cardiovascular Pharmacology, vol. 56, no. 2, pp. 141-146, 2010.

[7] M. S. Ewer, D. D. Von Hoff, and R. S. Benjamin, "A historical perspective of anthracycline cardiotoxicity," Heart Failure Clinics, vol. 7, no. 3, pp. 363-372, 2011.
[8] T. Force, D. S. Krause, and R. A. van Etten, "Molecular mechanisms of cardiotoxicity of tyrosine kinase inhibition," Nature Reviews Cancer, vol. 7, no. 5, pp. 332-344, 2007.

[9] G. W. De Keulenaer, K. Doggen, and K. Lemmens, "The vulnerability of the heart as a pluricellular paracrine organ: Lessons from unexpected triggers of heart failure in targeted ErbB2 anticancer therapy," Circulation Research, vol. 106, no. 1, pp. 35-46, 2010.

[10] H. Cheng and T. Force, "Molecular mechanisms of cardiovascular toxicity of targeted cancer therapeutics," Circulation Research, vol. 106, no. 1, pp. 21-34, 2010.

[11] T. Eschenhagen, T. Force, M. S. Ewer et al., "Cardiovascular side effects of cancer therapies: a position statement from the Heart Failure Association of the European Society of Cardiology," European Journal of Heart Failure, vol. 13, no. 1, pp. 1-10, 2011.

[12] P. Rizzo, D. Mele, C. Caliceti et al., "The role of notch in the cardiovascular system: potential adverse effects of investigational notch inhibitors," Frontiers in Oncology, vol. 4, article 384, 2015.

[13] M. S. Ewer, M. T. Vooletich, J.-B. Durand et al., "Reversibility of trastuzumab-related cardiotoxicity: new insights based on clinical course and response to medical treatment," Journal of Clinical Oncology, vol. 23, no. 31, pp. 7820-7826, 2005.

[14] D. B. Sawyer, C. Zuppinger, T. A. Miller, H. M. Eppenberger, and T. M. Suter, "Modulation of anthracycline-induced myofibrillar disarray in rat ventricular myocytes by neuregulin- $1 \beta$ and anti-erbB2: potential mechanism for trastuzumab-induced cardiotoxicity," Circulation, vol. 105, no. 13, pp. 1551-1554, 2002.

[15] Y. Octavia, C. G. Tocchetti, K. L. Gabrielson, S. Janssens, H. J. Crijns, and A. L. Moens, "Doxorubicin-induced cardiomyopathy: from molecular mechanisms to therapeutic strategies," Journal of Molecular and Cellular Cardiology, vol. 52, no. 6, pp. 1213-1225, 2012.

[16] A. M. C. Mavinkurve-Groothuis, K. A. Marcus, M. Pourier et al., "Myocardial 2D strain echocardiography and cardiac biomarkers in children during and shortly after anthracycline therapy for acute lymphoblastic leukaemia (ALL): a prospective study," European Heart Journal-Cardiovascular Imaging, vol. 14, no. 6, pp. 562-569, 2013.

[17] B. C. Drafts, K. M. Twomley, R. D’Agostino Jr. et al., "Low to moderate dose anthracycline-based chemotherapy is associated with early noninvasive imaging evidence of subclinical cardiovascular disease," JACC: Cardiovascular Imaging, vol. 6, no. 8, pp. 877-885, 2013.

[18] M. S. Ewer, M. K. Ali, B. Mackay et al., "A comparison of cardiac biopsy grades and ejection fraction estimations in patients receiving adriamycin," Journal of Clinical Oncology, vol. 2, no. 2, pp. 112-117, 1984.

[19] D. Cardinale, M. T. Sandri, A. Martinoni et al., "Myocardial injury revealed by plasma troponin I in breast cancer treated with high-dose chemotherapy," Annals of Oncology, vol. 13, no. 5, pp. 710-715, 2002.

[20] A. Allen, “The cardiotoxicity of chemotherapeutic drugs," Seminars in Oncology, vol. 19, no. 5, pp. 529-542, 1992.

[21] D. Jain, "Cardiotoxicity of doxorubicin and other anthracycline derivatives," Journal of Nuclear Cardiology, vol. 7, no. 1, pp. 53$62,2000$.

[22] S. M. Swain, F. S. Whaley, and M. S. Ewer, "Congestive heart failure in patients treated with doxorubicin: a retrospective analysis of three trials," Cancer, vol. 97, no. 11, pp. 2869-2879, 2003. 
[23] D. D. von Hoff, M. W. Layard, P. Basa et al., "Risk factors for doxorubicin-induced congestive heart failure," Annals of Internal Medicine, vol. 91, no. 5, pp. 710-717, 1979.

[24] T. Biancaniello, R. A. Meyer, K. Y. Wong, C. Sager, and S. Kaplan, "Doxorubicin cardiotoxicity in children," The Journal of Pediatrics, vol. 97, no. 1, pp. 45-50, 1980.

[25] L. Y. S. Godoy, J. Fukushige, H. Igarashi, A. Matsuzaki, and K. Ueda, "Anthracycline-induced cardiotoxicity in children with malignancies," Acta Paediatrica Japonica, vol. 39, no. 2, pp. 188193, 1997.

[26] S. E. Lipshultz, S. R. Lipsitz, S. M. Mone et al., "Female sex and higher drug dose as risk factors for late cardiotoxic effects of doxorubicin therapy for childhood cancer," The New England Journal of Medicine, vol. 332, no. 26, pp. 1738-1743, 1995.

[27] S. Zhang, X. Liu, T. Bawa-Khalfe et al., "Identification of the molecular basis of doxorubicin-induced cardiotoxicity," Nature Medicine, vol. 18, no. 11, pp. 1639-1642, 2012.

[28] D. B. Sawyer, "Anthracyclines and heart failure," The New England Journal of Medicine, vol. 368, no. 12, pp. 1154-1156, 2013.

[29] P. Menna, O. Gonzalez Paz, M. Chello, E. Covino, E. Salvatorelli, and G. Minotti, "Anthracycline cardiotoxicity," Expert Opinion on Drug Safety, vol. 11, no. S1, pp. S21-S36, 2012.

[30] V. Shalkey-Hahn, D. J. Lenihan, and B. Ky, "Cancer therapyinduced cardiotoxicity: basic mechanisms and potential cardioprotective therapies," Journal of the American Heart Association, vol. 3, no. 2, Article ID e000665, 2014.

[31] E. Salvatorelli, P. Menna, E. Cantalupo et al., "The concomitant management of cancer therapy and cardiac therapy," Biochimica et Biophysica Acta, 2015.

[32] P. Spallarossa, P. Altieri, C. Aloi et al., "Doxorubicin induces senescence or apoptosis in rat neonatal cardiomyocytes by regulating the expression levels of the telomere binding factors 1 and 2," The American Journal of Physiology-Heart and Circulatory Physiology, vol. 297, no. 6, pp. H2169-H2181, 2009.

[33] D. L. Hershman, R. B. McBride, A. Eisenberger, Y. T. Wei, V. R. Grann, and J. S. Jacobson, "Doxorubicin, cardiac risk factors, and cardiac toxicity in elderly patients with diffuse B-cell nonHodgkin's lymphoma," Journal of Clinical Oncology, vol. 26, no. 19, pp. 3159-3165, 2008.

[34] P. Fabbi, P. Spallarossa, S. Garibaldi et al., "Doxorubicin impairs the insulin-like growth factor-1 system and causes insulin-like growth factor-1 resistance in cardiomyocytes," PLOS ONE, vol. 10, no. 5, Article ID e0124643, 2015.

[35] L. Prezioso, S. Tanzi, F. Galaverna et al., "Cancer treatmentinduced cardiotoxicity: a cardiac stem cell disease?" Cardiovascular \& Hematological Agents in Medicinal Chemistry, vol. 8, no. 1, pp. 55-75, 2010.

[36] E. Piegari, A. de Angelis, D. Cappetta et al., "Doxorubicin induces senescence and impairs function of human cardiac progenitor cells," Basic Research in Cardiology, vol. 108, article 334, 2013.

[37] P. Spallarossa, P. Altieri, S. Garibaldi et al., "Matrix metalloproteinase- 2 and -9 are induced differently by doxorubicin in H9c2 cells: the role of MAP kinases and NAD(P)H oxidase," Cardiovascular Research, vol. 69, no. 3, pp. 736-745, 2006.

[38] A. Goetzenich, N. Hatam, A. Zernecke et al., "Alteration of matrix metalloproteinases in selective left ventricular adriamycin-induced cardiomyopathy in the pig," Journal of Heart and Lung Transplantation, vol. 28, no. 10, pp. 1087-1093, 2009.
[39] Y. Ma, T. Yamazaki, H. Yang et al., “Tumor necrosis factor is dispensable for the success of immunogenic anticancer chemotherapy," OncoImmunology, vol. 2, no. 6, Article ID e24786, 2013.

[40] K. A. D. Sauter, L. J. Wood, J. Wong, M. Iordanov, and B. E. Magun, "Doxorubicin and daunorubicin induce processing and release of interleukin- $1 \beta$ through activation of the NLRP3 inflammasome," Cancer Biology and Therapy, vol. 11, no. 12, pp. 1008-1016, 2011.

[41] S. Saletan, "Mitoxantrone: an active, new antitumor agent with an improved therapeutic index," Cancer Treatment Reviews, vol. 14, no. 3-4, pp. 297-303, 1987.

[42] A. C. Broverman, J. H. Antin, M. T. Plappert, E. F. Cook, and R. T. Lee, "Cyclophosphamide cardiotoxicity in bone marrow transplantation: a prospective evaluation of new dosing regimens," Journal of Clinical Oncology, vol. 9, no. 7, pp. 1215$1223,1991$.

[43] R. Altena, Y. M. Hummel, J. Nuver et al., "Longitudinal changes in cardiac function after cisplatin-based chemotherapy for testicular cancer," Annals of Oncology, vol. 22, no. 10, pp. 22862293, 2011.

[44] D. Slamon, W. Eiermann, N. Robert et al., "Adjuvant trastuzumab in HER2-positive breast cancer," The New England Journal of Medicine, vol. 365, no. 14, pp. 1273-1283, 2011.

[45] G. Curigliano, D. Cardinale, T. Suter et al., "Cardiovascular toxicity induced by chemotherapy, targeted agents and radiotherapy: ESMO clinical practice guidelines," Annals of Oncology, vol. 23, supplement 7, pp. vii155-vii166, 2012.

[46] C. C. Meyer, K. A. Calis, L. B. Burke, C. A. Walawander, and T. H. Grasela, "Symptomatic cardiotoxicity associated with 5fluorouracil," Pharmacotherapy, vol. 17, no. 4, pp. 729-736, 1997.

[47] E. Van Cutsem, P. M. Hoff, J. L. Blum, M. Abt, and B. Osterwalder, "Incidence of cardiotoxicity with the oral fluoropyrimidine capecitabine is typical of that reported with 5fluorouracil," Annals of Oncology, vol. 13, no. 3, pp. 484-485, 2002.

[48] E. T. Yeh and C. L. Bickford, "Cardiovascular complications of cancer therapy: incidence, pathogenesis, diagnosis, and management," Journal of the American College of Cardiology, vol. 53, no. 24, pp. 2231-2247, 2009.

[49] M. de Forni, M. C. Malet-Martino, P. Jaillais et al., "Cardiotoxicity of high-dose continuous infusion fluorouracil: a prospective clinical study," Journal of Clinical Oncology, vol. 10, pp. 1795$1801,1992$.

[50] C. Kosmas, M. S. Kallistratos, P. Kopterides et al., "Cardiotoxicity of fluoropyrimidines in different schedules of administration: a prospective study," Journal of Cancer Research and Clinical Oncology, vol. 134, no. 1, pp. 75-82, 2008.

[51] N. Frickhofen, F.-J. Beck, B. Jung, H.-G. Fuhr, H. Andrasch, and M. Sigmund, "Capecitabine can induce acute coronary syndrome similar to 5-fluorouracil," Annals of Oncology, vol. 13, no. 5, pp. 797-801, 2002.

[52] M. W. Saif, M. Tomita, L. Ledbetter, and R. B. Diasio, "Capecitabine-related cardiotoxicity: recognition and management," Journal of Supportive Oncology, vol. 6, no. 1, pp. 41-48, 2008.

[53] N. J. Freeman and M. E. Costanza, "5-Fluorouracil-associated cardiotoxicity," Cancer, vol. 61, no. 1, pp. 36-45, 1988.

[54] C. Focaccetti, A. Bruno, E. Magnani et al., "Effects of 5fluorouracil on morphology, cell cycle, proliferation, apoptosis, 
autophagy and ros production in endothelial cells and cardiomyocytes," PLoS ONE, vol. 10, no. 2, Article ID e0115686, 2015.

[55] D. J. Slamon, G. M. Clark, S. G. Wong, W. J. Levin, A. Ullrich, and W. L. McGuire, "Human breast cancer: correlation of relapse and survival with amplification of the HER-2/neu oncogene," Science, vol. 235, no. 4785, pp. 182-191, 1987.

[56] D. J. Slamon, B. Leyland-Jones, S. Shak et al., "Use of chemotherapy plus a monoclonal antibody against her2 for metastatic breast cancer that overexpresses HER2," The New England Journal of Medicine, vol. 344, no. 11, pp. 783-792, 2001.

[57] C. G. Tocchetti, G. Ragone, C. Coppola et al., "Detection, monitoring, and management of trastuzumab-induced left ventricular dysfunction: an actual challenge," European Journal of Heart Failure, vol. 14, no. 2, pp. 130-137, 2012.

[58] M. S. Ewer and S. M. Lippman, "Type II chemotherapy-related cardiac dysfunction: time to recognize a new entity," Journal of Clinical Oncology, vol. 23, no. 13, pp. 2900-2902, 2005.

[59] M. S. Ewer and S. M. Ewer, "Troponin I provides insight into cardiotoxicity and the anthracycline-trastuzumab interaction," Journal of Clinical Oncology, vol. 28, no. 25, pp. 3901-3904, 2010.

[60] O. Odiete, M. F. Hill, and D. B. Sawyer, "Neuregulin in cardiovascular development and disease," Circulation Research, vol. 111, no. 10, pp. 1376-1385, 2012.

[61] S. A. Crone, Y.-Y. Zhao, L. Fan et al., "ErbB2 is essential in the prevention of dilated cardiomyopathy," Nature Medicine, vol. 8, no. 5, pp. 459-465, 2002.

[62] K. Gabrielson, D. Bedja, S. Pin et al., "Heat shock protein 90 and ErbB2 in the cardiac response to doxorubicin injury," Cancer Research, vol. 67, no. 4, pp. 1436-1441, 2007.

[63] F. Timolati, D. Ott, L. Pentassuglia et al., "Neuregulin-1 beta attenuates doxorubicin-induced alterations of excitationcontraction coupling and reduces oxidative stress in adult rat cardiomyocytes," Journal of Molecular and Cellular Cardiology, vol. 41, no. 5, pp. 845-854, 2006.

[64] L. Pentassuglia, M. Graf, H. Lane et al., "Inhibition of ErbB2 by receptor tyrosine kinase inhibitors causes myofibrillar structural damage without cell death in adult rat cardiomyocytes," Experimental Cell Research, vol. 315, no. 7, pp. 1302-1312, 2009.

[65] C. L. Galindo, S. Ryzhov, and D. B. Sawyer, "Neuregulin as a heart failure therapy and mediator of reverse remodeling," Current Heart Failure Reports, vol. 11, no. 1, pp. 40-49, 2014.

[66] R. M. Steingart, G. L. Bakris, H. X. Chen et al., "Management of cardiac toxicity in patients receiving vascular endothelial growth factor signaling pathway inhibitors," American Heart Journal, vol. 163, no. 2, pp. 156-163, 2012.

[67] C. G. Tocchetti, G. Gallucci, C. Coppola et al., "The emerging issue of cardiac dysfunction induced by antineoplastic angiogenesis inhibitors,' European Journal of Heart Failure, vol. 15, no. 5, pp. 482-489, 2013.

[68] J. Folkman, "Tumor angiogenesis: therapeutic implications," The New England Journal of Medicine, vol. 285, no. 21, pp. 11821186, 1971.

[69] J. Folkman, "Angiogenesis: an organizing principle for drug discovery?" Nature Reviews Drug Discovery, vol. 6, no. 4, pp. 273-286, 2007.

[70] G. Marone and F. Granata, "Angiogenesis, lymphangiogenesis and clinical implications. Preface," Chemical Immunology and Allergy, vol. 99, pp. 11-12, 2014.
[71] M. Schmidinger, C. C. Zielinski, U. M. Vogl et al., "Cardiac toxicity of sunitinib and sorafenib in patients with metastatic renal cell carcinoma," Journal of Clinical Oncology, vol. 26, no. 32, pp. 5204-5212, 2008.

[72] S. M. Gressett and S. R. Shah, "Intricacies of bevacizumabinduced toxicities and their management," Annals of Pharmacotherapy, vol. 43, no. 3, pp. 490-501, 2009.

[73] J. Welti, S. Loges, S. Dimmeler, and P. Carmeliet, "Recent molecular discoveries in angiogenesis and antiangiogenic therapies in cancer," The Journal of Clinical Investigation, vol. 123, no. 8, pp. 3190-3200, 2013.

[74] M. Sano, T. Minamino, H. Toko et al., "p53-induced inhibition of Hif-1 causes cardiac dysfunction during pressure overload," Nature, vol. 446, no. 7134, pp. 444-448, 2007.

[75] K. Walsh and I. Shiojima, "Cardiac growth and angiogenesis coordinated by intertissue interactions," The Journal of Clinical Investigation, vol. 117, no. 11, pp. 3176-3179, 2007.

[76] D. May, D. Gilon, V. Djonov et al., "Transgenic system for conditional induction and rescue of chronic myocardial hibernation provides insights into genomic programs of hibernation," Proceedings of the National Academy of Sciences of the United States of America, vol. 105, no. 1, pp. 282-287, 2008.

[77] H. Hurwitz, L. Fehrenbacher, W. Novotny et al., "Bevacizumab plus irinotecan, fluorouracil, and leucovorin for metastatic colorectal cancer," The New England Journal of Medicine, vol. 350, no. 23, pp. 2335-2342, 2004.

[78] A. Sandler, R. Gray, M. C. Perry et al., "Paclitaxel-carboplatin alone or with bevacizumab for non-small-cell lung cancer," The New England Journal of Medicine, vol. 355, no. 24, pp. 25422550, 2006.

[79] K. D. Miller, L. I. Chap, F. A. Holmes et al., "Randomized phase III trial of capecitabine compared with bevacizumab plus capecitabine in patients with previously treated metastatic breast cancer," Journal of Clinical Oncology, vol. 23, no. 4, pp. 792-799, 2005.

[80] V. Chintalgattu, D. Ai, R. R. Langley et al., "Cardiomyocyte PDGFR- $\beta$ signaling is an essential component of the mouse cardiac response to load-induced stress," Journal of Clinical Investigation, vol. 120, no. 2, pp. 472-484, 2010.

[81] B. B. Hasinoff and D. Patel, "The lack of target specificity of small molecule anticancer kinase inhibitors is correlated with their ability to damage myocytes in vitro," Toxicology and Applied Pharmacology, vol. 249, no. 2, pp. 132-139, 2010.

[82] T. F. Chu, M. A. Rupnick, R. Kerkela et al., "Cardiotoxicity associated with tyrosine kinase inhibitor sunitinib," The Lancet, vol. 370, no. 9604, pp. 2011-2019, 2007.

[83] A. Y. Khakoo, C. M. Kassiotis, N. Tannir et al., "Heart failure associated with sunitinib malate: a multitargeted receptor tyrosine kinase inhibitor," Cancer, vol. 112, no. 11, pp. 2500-2508, 2008.

[84] R. J. Motzer, T. E. Hutson, P. Tomczak et al., "Sunitinib versus interferon alfa in metastatic renal-cell carcinoma," The New England Journal of Medicine, vol. 356, no. 2, pp. 115-124, 2007.

[85] M. L. Telli, R. M. Witteles, G. A. Fisher, and S. Srinivas, "Cardiotoxicity associated with the cancer therapeutic agent sunitinib malate," Annals of Oncology, vol. 19, no. 9, pp. 1613$1618,2008$.

[86] A. Anisimov, A. Alitalo, P. Korpisalo et al., "Activated forms of VEGF-C and VEGF-D provide improved vascular function in skeletal muscle," Circulation Research, vol. 104, no. 11, pp. 13021312, 2009. 
[87] S. Loges, C. Roncal, and P. Carmeliet, "Development of targeted angiogenic medicine," Journal of Thrombosis and Haemostasis, vol. 7, no. 1, pp. 21-33, 2009.

[88] Y. Izumiya, I. Shiojima, K. Sato, D. B. Sawyer, W. S. Colucci, and K. Walsh, "Vascular endothelial growth factor blockade promotes the transition from compensatory cardiac hypertrophy to failure in response to pressure overload," Hypertension, vol. 47, no. 5, pp. 887-893, 2006.

[89] B. I. Lévy, "Microvascular plasticity and experimental heart failure," Hypertension, vol. 47, no. 5, pp. 827-829, 2006.

[90] R. A. De Boer, Y. M. Pinto, and D. J. Van Veldhuisen, "The imbalance between oxygen demand and supply as a potential mechanism in the pathophysiology of heart failure: the role of microvascular growth and abnormalities," Microcirculation, vol. 10, no. 2, pp. 113-126, 2003.

[91] R. Kerkela, K. C. Woulfe, J.-B. Durand et al., "Sunitinib-induced cardiotoxicity is mediated by off-target inhibition of AMPactivated protein kinase," Clinical and Translational Science, vol. 2, no. 1, pp. 15-25, 2009.

[92] P. P. Rainer, B. Doleschal, J. A. Kirk et al., "Sunitinib causes dose-dependent negative functional effects on myocardium and cardiomyocytes," BJU International, vol. 110, no. 10, pp. 14551462, 2012.

[93] G. Di Lorenzo, R. Autorino, G. Bruni et al., "Cardiovascular toxicity following sunitinib therapy in metastatic renal cell carcinoma: a multicenter analysis," Annals of Oncology, vol. 20, no. 9, pp. 1535-1542, 2009.

[94] C. J. Richards, Y. Je, F. A. B. Schutz et al., "Incidence and risk of congestive heart failure in patients with renal and nonrenal cell carcinoma treated with sunitinib," Journal of Clinical Oncology, vol. 29, no. 25, pp. 3450-3456, 2011.

[95] N. Feng, S. Huke, G. Zhu et al., "Constitutive BDNF/TrkB signaling is required for normal cardiac contraction and relaxation," Proceedings of the National Academy of Sciences, vol. 112, no. 6, pp. 1880-1885, 2015.

[96] T. Force and K. L. Kolaja, "Cardiotoxicity of kinase inhibitors: the prediction and translation of preclinical models to clinical outcomes," Nature Reviews Drug Discovery, vol. 10, no. 2, pp. 111-126, 2011.

[97] J. Mourad and B. I. Levy, "Mechanisms of antiangiogenicinduced arterial hypertension," Current Hypertension Reports, vol. 13, no. 4, pp. 289-293, 2011.

[98] R. Goodwin, K. Ding, L. Seymour et al., “Treatment-emergent hypertension and outcomes in patients with advanced nonsmall-cell lung cancer receiving chemotherapy with or without the vascular endothelial growth factor receptor inhibitor cediranib: NCIC Clinical Trials Group Study BR24," Annals of Oncology, vol. 21, no. 11, pp. 2220-2226, 2010.

[99] M. Scartozzi, E. Galizia, S. Chiorrini et al., "Arterial hypertension correlates with clinical outcome in colorectal cancer patients treated with first-line bevacizumab," Annals of Oncology, vol. 20, no. 2, pp. 227-230, 2009.

[100] R. Kerkelä, L. Grazette, R. Yacobi et al., "Cardiotoxicity of the cancer therapeutic agent imatinib mesylate," Nature Medicine, vol. 12, no. 8, pp. 908-916, 2006.

[101] E. Atallah, J.-B. Durand, H. Kantarjian, and J. Cortes, "Congestive heart failure is a rare event in patients receiving imatinib therapy," Blood, vol. 110, no. 4, pp. 1233-1237, 2007.

[102] A. Nohria, " $\beta$-Adrenergic blockade for anthracycline- and trastuzumab-induced cardiotoxicity: is prevention better than cure?" Circulation: Heart Failure, vol. 6, no. 3, pp. 358-361, 2013.
[103] M. L. Maitland, G. L. Bakris, H. R. Black et al., "Initial assessment, surveillance, and management of blood pressure in patients receiving vascular endothelial growth factor signaling pathway inhibitors," Journal of the National Cancer Institute, vol. 102, pp. 596-604, 2010.

[104] J. R. Carver, S. J. Schuster, and J. H. Glick, "Doxorubicin cardiotoxicity in the elderly: old drugs and new opportunities," Journal of Clinical Oncology, vol. 26, no. 19, pp. 3122-3124, 2008.

[105] P. Lancellotti, S. D. Anker, E. Donal et al., "EACVI/HFA Cardiac Oncology Toxicity Registry in breast cancer patients: rationale, study design, and methodology (EACVI/HFA COT Registry)EURObservational Research Program of the European Society of Cardiology," European Heart Journal Cardiovascular Imaging, vol. 16, no. 5, pp. 466-470, 2015.

[106] C. Fedele, G. Riccio, C. Coppola et al., "Comparison of preclinical cardiotoxic effects of different ErbB2 inhibitors," Breast Cancer Research and Treatment, vol. 133, no. 2, pp. 511-521, 2012.

[107] P. Thavendiranathan, F. Poulin, K.-D. Lim, J. C. Plana, A. Woo, and T. H. Marwick, "Use of myocardial strain imaging by echocardiography for the early detection of cardiotoxicity in patients during and after cancer chemotherapy: a systematic review," Journal of the American College of Cardiology, vol. 63, no. 25, part A, pp. 2751-2768, 2014.

[108] D. S. Ong, M. Scherrer-Crosbie, O. Coelho-Filho, S. A. Francis, and T. G. Neilan, "Imaging methods for detection of chemotherapy-associated cardiotoxicity and dysfunction," Expert Review of Cardiovascular Therapy, vol. 12, no. 4, pp. 487497, 2014.

[109] M. S. Ewer and D. J. Lenihan, "Left ventricular ejection fraction and cardiotoxicity: is our ear really to the ground?" Journal of Clinical Oncology, vol. 26, no. 8, pp. 1201-1203, 2008.

[110] N. Fallah-Rad, J. R. Walker, A. Wassef et al., "The utility of cardiac biomarkers, tissue velocity and strain imaging, and cardiac magnetic resonance imaging in predicting early left ventricular dysfunction in patients with human epidermal growth factor receptor II-positive breast cancer treated with adjuvant trastuzumab therapy," Journal of the American College of Cardiology, vol. 57, no. 22, pp. 2263-2270, 2011.

[111] D. Cardinale, A. Colombo, R. Torrisi et al., "Trastuzumabinduced cardiotoxicity: clinical and prognostic implications of troponin I evaluation," Journal of Clinical Oncology, vol. 28, no. 25, pp. 3910-3916, 2010.

[112] J. Walker, N. Bhullar, N. Fallah-Rad et al., "Role of threedimensional echocardiography in breast cancer: comparison with two-dimensional echocardiography, multiple-gated acquisition scans, and cardiac magnetic resonance imaging," Journal of Clinical Oncology, vol. 28, no. 21, pp. 3429-3436, 2010.

[113] D. S. Jassal, S.-Y. Han, C. Hans et al., "Utility of tissue Doppler and strain rate imaging in the early detection of trastuzumab and anthracycline mediated cardiomyopathy," Journal of the American Society of Echocardiography, vol. 22, no. 4, pp. 418424, 2009.

[114] J. L. Hare, J. K. Brown, R. Leano, C. Jenkins, N. Woodward, and T. H. Marwick, "Use of myocardial deformation imaging to detect preclinical myocardial dysfunction before conventional measures in patients undergoing breast cancer treatment with trastuzumab," American Heart Journal, vol. 158, no. 2, pp. 294301, 2009.

[115] E. Ho, A. Brown, P. Barrett et al., "Subclinical anthracycline- and trastuzumab-induced cardiotoxicity in the long-term followup of asymptomatic breast cancer survivors: a speckle tracking echocardiographic study," Heart, vol. 96, no. 9, pp. 701-707, 2010. 
[116] H. Sawaya, I. A. Sebag, J. C. Plana et al., "Early detection and prediction of cardiotoxicity in chemotherapy-treated patients," American Journal of Cardiology, vol. 107, no. 9, pp. 1375-1380, 2011.

[117] R. Hoffmann, S. von Bardeleben, F. ten Cate et al., "Assessment of systolic left ventricular function: a multi-centre comparison of cineventriculography, cardiac magnetic resonance imaging, unenhanced and contrast-enhanced echocardiography," European Heart Journal, vol. 26, no. 6, pp. 607-616, 2005.

[118] S. Malm, S. Frigstad, E. Sagberg, H. Larsson, and T. Skjaerpe, "Accurate and reproducible measurement of left ventricular volume and ejection fraction by contrast echocardiography: a comparison with magnetic resonance imaging," Journal of the American College of Cardiology, vol. 44, no. 5, pp. 1030-1035, 2004.

[119] T. M. Markman and M. Markman, "Cardiotoxicity of antineoplastic agents: what is the present and future role for imaging?" Current Oncology Reports, vol. 16, no. 8, article 396, 2014.

[120] M. Jarfelt, V. Kujacic, D. Holmgren, R. Bjarnason, and B. Lannering, "Exercise echocardiography reveals subclinical cardiac dysfunction in young adult survivors of childhood acute lymphoblastic leukemia," Pediatric Blood and Cancer, vol. 49, no. 6, pp. 835-840, 2007.

[121] M. Maiello, R. K. Sharma, M. M. Ciccone et al., "Early diagnosis of cardiac toxicity related to antineoplastic treatment," Journal of Cancer Therapy, vol. 2, no. 2, pp. 161-166, 2011.

[122] S. Tassan-Mangina, D. Codorean, M. Metivier et al., "Tissue Doppler imaging and conventional echocardiography after anthracycline treatment in adults: early and late alterations of left ventricular function during a prospective study," European Journal of Echocardiography, vol. 7, no. 2, pp. 141-146, 2006.

[123] S. Wakasugi, A. Wada, Y. Hasegawa, S. Nakano, and N. Shibata, "Detection of abnormal cardiac adrenergic neuron activity in adriamycin-induced cardiomyopathy with iodine125-metaiodobenzylguanidine," Journal of Nuclear Medicine, vol. 33, no. 2, pp. 208-214, 1992.

[124] T. Higuchi and M. Schwaiger, "Imaging cardiac neuronal function and dysfunction," Current Cardiology Reports, vol. 8, no. 2, pp. 131-138, 2006.

[125] C. L. Maini, R. Sciuto, A. Ferraironi et al., "Clinical relevance of radionuclide angiography and antimyosin immunoscintigraphy for risk assessment in epirubicin cardiotoxicity," Journal of Nuclear Cardiology, vol. 4, no. 6, pp. 502-508, 1997.

[126] R. A. V. Olmos, I. Carrió, C. A. Hoefnagel et al., "High sensitivity of radiolabelled antimyosin scintigraphy in assessing anthracycline related early myocyte damage preceding cardiac dysfunction," Nuclear Medicine Communications, vol. 23, no. 9, pp. 871-877, 2002.

[127] T. M. Behr, M. Behe, B. Wormann et al., "Trastuzumab and breast cancer," The New England Journal of Medicine, vol. 345, pp. 995-998, 2001.

[128] P. J. Perik, M. N. Lub-De Hooge, J. A. Gietema et al., "Indium111-labeled trastuzumab scintigraphy in patients with human epidermal growth factor receptor 2-positive metastatic breast cancer," Journal of Clinical Oncology, vol. 24, no. 15, pp. 22762282, 2006.

[129] T. Suzuki, D. Hayashi, T. Yamazaki et al., "Elevated B-type natriuretic peptide levels after anthracycline administration," American Heart Journal, vol. 136, no. 2, pp. 362-363, 1998.

[130] G. Daugaard, U. Lassen, P. Bie et al., "Natriuretic peptides in the monitoring of anthracycline induced reduction in left ventricular ejection fraction," European Journal of Heart Failure, vol. 7, no. 1, pp. 87-93, 2005.

[131] S. E. Lipshultz, N. Rifai, S. E. Sallan et al., "Predictive value of cardiac troponin $\mathrm{T}$ in pediatric patients at risk for myocardial injury," Circulation, vol. 96, no. 8, pp. 2641-2648, 1997.

[132] D. Cardinale, M. T. Sandri, A. Colombo et al., "Prognostic value of troponin I in cardiac risk stratification of cancer patients undergoing high-dose chemotherapy," Circulation, vol. 109, no. 22, pp. 2749-2754, 2004.

[133] B. Ky, M. Putt, H. Sawaya et al., "Early increases in multiple biomarkers predict subsequent cardiotoxicity in patients with breast cancer treated with doxorubicin, taxanes, and trastuzumab," Journal of the American College of Cardiology, vol. 63, no. 8, pp. 809-816, 2014.

[134] A. Albini, G. Pennesi, F. Donatelli, R. Cammarota, S. De Flora, and D. M. Noonan, "Cardiotoxicity of anticancer drugs: the need for cardio-oncology and cardio-oncological prevention," Journal of the National Cancer Institute, vol. 102, no. 1, pp. 14$25,2010$.

[135] K. C. Oeffinger, A. C. Mertens, C. A. Sklar et al., "Chronic health conditions in adult survivors of childhood cancer," The New England Journal of Medicine, vol. 355, no. 15, pp. 1572-1582, 2006.

[136] M. Lamberti, M. Caraglia, S. Zappavigna et al., "Evaluation in vitro of the cardiotoxic effects of 5-fluorouracil for the prevention of cardiovascular damage in health workers occupationally exposed," Giornale Italiano di Medicina del Lavoro ed Ergonomia, vol. 33, no. 3, supplement, pp. 298-302, 2011.

[137] T. M. Suter, M. Procter, D. J. Van Veldhuisen et al., "Trastuzumab-associated cardiac adverse effects in the herceptin adjuvant trial," Journal of Clinical Oncology, vol. 25, no. 25, pp. 3859-3865, 2007.

[138] J. Rickard, D. J. Kumbhani, B. Baranowski, D. O. Martin, W. H. Tang, and B. L. Wilkoff, "Usefulness of cardiac resynchronization therapy in patients with Adriamycin-induced cardiomyopathy," American Journal of Cardiology, vol. 105, no. 4, pp. 522-526, 2010.

[139] C. W. Yancy, M. Jessup, B. Bozkurt et al., "2013 ACCF/AHA guideline for the management of heart failure: a report of the american college of cardiology foundation/american heart association task force on practice guidelines," Circulation, vol. 128, no. 16, pp. e240-e327, 2013.

[140] M. S. Ewer and S. M. Ewer, "Cardiotoxicity of anticancer treatments: what the cardiologist needs to know," Nature Reviews Cardiology, vol. 7, no. 10, pp. 564-575, 2010.

[141] D. B. Sawyer, X. Peng, B. Chen, L. Pentassuglia, and C. C. Lim, "Mechanisms of anthracycline cardiac injury: can we identify strategies for cardioprotection?" Progress in Cardiovascular Diseases, vol. 53, no. 2, pp. 105-113, 2010.

[142] G. J. Yoon, M. L. Telli, D. P. Kao, K. Y. Matsuda, R. W. Carlson, and R. M. Witteles, "Left ventricular dysfunction in patients receiving cardiotoxic cancer therapies: are clinicians responding optimally?" Journal of the American College of Cardiology, vol. 56, no. 20, pp. 1644-1650, 2010.

[143] E. Pituskin, M. Haykowsky, J. R. Mackey et al., "Rationale and design of the Multidisciplinary Approach to Novel Therapies in Cardiology Oncology Research Trial (MANTICORE 101-Breast): a randomized, placebo-controlled trial to determine if conventional heart failure pharmacotherapy can prevent trastuzumab-mediated left ventricular remodeling among 
patients with HER2+ early breast cancer using cardiac MRI," BMC Cancer, vol. 11, article 318, 2011.

[144] X. Bosch, M. Rovira, M. Sitges et al., "Enalapril and carvedilol for preventing chemotherapy-induced left ventricular systolic dysfunction in patients with malignant hemopathies: the OVERCOME trial (prevention of left Ventricular dysfunction with Enalapril and carvedilol in patients submitted to intensive Chemotherapy for the treatment of Malignant hemopathies)," Journal of the American College of Cardiology, vol. 61, no. 23, pp. 2355-2362, 2013.

[145] D. Cardinale, A. Colombo, G. Lamantia et al., "Anthracyclineinduced cardiomyopathy: clinical relevance and response to pharmacologic therapy," Journal of the American College of Cardiology, vol. 55, no. 3, pp. 213-220, 2010.

[146] P. Vejpongsa and E. T. H. Yeh, "Prevention of anthracyclineinduced cardiotoxicity: challenges and opportunities," Journal of the American College of Cardiology, vol. 64, no. 9, pp. 938945, 2014.

[147] E. C. van Dalen, H. N. Caron, H. O. Dickinson, and L. C. Kremer, "Cardioprotective interventions for cancer patients receiving anthracyclines," Cochrane Database of Systematic Reviews, no. 6, Article ID CD003917, 2011.

[148] D. Cardinale, A. Colombo, M. T. Sandri et al., "Prevention of high-dose chemotherapy-induced cardiotoxicity in highrisk patients by angiotensin-converting enzyme inhibition," Circulation, vol. 114, no. 23, pp. 2474-2481, 2006.

[149] Z. Acar, A. Kale, M. Turgut et al., "Efficiency of atorvastatin in the protection of anthracycline-induced cardiomyopathy," Journal of the American College of Cardiology, vol. 58, no. 9, pp. 988-989, 2011.

[150] S. Seicean, A. Seicean, J. C. Plana, G. T. Budd, and T. H. Marwick, "Effect of statin therapy on the risk for incident heart failure in patients with breast cancer receiving anthracycline chemotherapy: an observational clinical cohort study," Journal of the American College of Cardiology, vol. 60, no. 23, pp. 23842390, 2012.

[151] S. Seicean, A. Seicean, N. Alan, J. C. Plana, G. T. Budd, and T. H. Marwick, "Cardioprotective effect of $\beta$-adrenoceptor blockade in patients with breast cancer undergoing chemotherapy: follow-up study of heart failure," Circulation: Heart Failure, vol. 6, no. 3, pp. 420-426, 2013.

[152] N. Kalay, E. Basar, I. Ozdogru et al., "Protective effects of carvedilol against anthracycline-induced cardiomyopathy," Journal of the American College of Cardiology, vol. 48, no. 11, pp. 2258-2262, 2006.

[153] G. Fajardo, M. Zhao, J. Powers, and D. Bernstein, "Differential cardiotoxic/cardioprotective effects of $\beta$-adrenergic receptor subtypes in myocytes and fibroblasts in doxorubicin cardiomyopathy," Journal of Molecular and Cellular Cardiology, vol. 40, no. 3, pp. 375-383, 2006.

[154] G. Fajardo, M. Zhao, G. Berry, L.-J. Wong, D. Mochly-Rosen, and D. Bernstein, " $\beta 2$-adrenergic receptors mediate cardioprotection through crosstalk with mitochondrial cell death pathways," Journal of Molecular and Cellular Cardiology, vol. 51, no. 5, pp. 781-789, 2011.

[155] G. C. Fonarow, "Role of carvedilol controlled-release in cardiovascular disease," Expert Review of Cardiovascular Therapy, vol. 7, no. 5, pp. 483-498, 2009.

[156] P. Spallarossa, S. Garibaldi, P. Altieri et al., "Carvedilol prevents doxorubicin-induced free radical release and apoptosis in cardiomyocytes in vitro," Journal of Molecular and Cellular Cardiology, vol. 37, no. 4, pp. 837-846, 2004.

[157] W. Arozal, F. R. Sari, K. Watanabe et al., "Carvedilol-afforded protection against daunorubicin-induced cardiomyopathic rats in vivo: effects on cardiac fibrosis and hypertrophy," ISRN Pharmacology, vol. 2011, Article ID 430549, 8 pages, 2011.

[158] W. Arozal, K. Watanabe, P. T. Veeraveedu et al., "Protective effect of carvedilol on daunorubicin-induced cardiotoxicity and nephrotoxicity in rats," Toxicology, vol. 274, no. 1-3, pp. 18-26, 2010.

[159] W. Arozal, K. Watanabe, P. T. Veeraveedu et al., "Effect of telmisartan in limiting the cardiotoxic effect of daunorubicin in rats," Journal of Pharmacy and Pharmacology, vol. 62, no. 12, pp. 1776-1783, 2010.

[160] W. Arozal, K. Watanabe, P. T. Veeraveedu et al., "Beneficial effects of angiotensin II receptor blocker, olmesartan, in limiting the cardiotoxic effect of daunorubicin in rats," Free Radical Research, vol. 44, no. 11, pp. 1369-1377, 2010.

[161] F. de Nigris, M. Rienzo, C. Schiano, C. Fiorito, A. Casamassimi, and C. Napoli, "Prominent cardioprotective effects of third generation beta blocker nebivolol against anthracycline-induced cardiotoxicity using the model of isolated perfused rat heart," European Journal of Cancer, vol. 44, no. 3, pp. 334-340, 2008.

[162] P. Norman, "Kinase therapeutic pipelines: an assessment of targets and agents in development," Insight Pharma Reports, 2007, http://www.insightpharmareports.com/reports/2007/90_ Kinase_Inhibitors/overview.asp.

[163] P. W. Fisher, F. Salloum, A. Das, H. Hyder, and R. C. Kukreja, "Phosphodiesterase-5 inhibition with sildenafil attenuates cardiomyocyte apoptosis and left ventricular dysfunction in a chronic model of doxorubicin cardiotoxicity," Circulation, vol. 111, no. 13, pp. 1601-1610, 2005.

[164] A. Das, D. Durrant, F. N. Salloum, L. Xi, and R. C. Kukreja, "PDE5 inhibitors as therapeutics for heart disease, diabetes and cancer," Pharmacology \& Therapeutics, vol. 147, pp. 12-21, 2015.

[165] C. G. Tocchetti, A. Carpi, C. Coppola et al., "Ranolazine protects from doxorubicin-induced oxidative stress and cardiac dysfunction," European Journal of Heart Failure, vol. 16, no. 4, pp. 358-366, 2014.

[166] K. Lemmens and G. W. De Keulenaer, "Paving new paths for neuregulin-1-assisted cardiac regenerative medicine. focus on improving murine embryonic stem cell differentiation into cardiomyocytes with neuregulin-1: differential expression of microRNA,' The American Journal of Physiology-Cell Physiology, vol. 301, no. 1, pp. C16-C17, 2011.

[167] P. Sysa-Shah, Y. Xu, X. Guo et al., "Cardiac-specific overexpression of epidermal growth factor receptor 2 (ErbB2) induces pro-survival pathways and hypertrophic cardiomyopathy in mice," PLoS ONE, vol. 7, no. 8, Article ID e42805, 2012.

[168] A. Gupta, C. Rohlfsen, M. K. Leppo et al., "Creatine kinaseoverexpression improves myocardial energetics, contractile dysfunction and survival in murine doxorubicin cardiotoxicity," PLoS ONE, vol. 8, no. 10, Article ID e74675, 2013.

[169] J. X. Wang, X. J. Zhang, C. Feng et al., "MicroRNA-532-3p regulates mitochondrial fission through targeting apoptosis repressor with caspase recruitment domain in doxorubicin cardiotoxicity," Cell Death and Disease, vol. 6, no. 3, Article ID e1677, 2015.

[170] G. Tarone, J.-L. Balligand, J. Bauersachs et al., “Targeting myocardial remodelling to develop novel therapies for heart 
failure: a position paper from the Working Group on Myocardial Function of the European Society of Cardiology," European Journal of Heart Failure, vol. 16, no. 5, pp. 494-508, 2014.

[171] R. Kumarswamy and T. Thum, "Non-coding RNAs in cardiac remodeling and heart failure," Circulation Research, vol. 113, no. 6, pp. 676-689, 2013.

[172] S. T. Pleger, H. Brinks, J. Ritterhoff et al., "Heart failure gene therapy: the path to clinical practice," Circulation Research, vol. 113, no. 6, pp. 792-809, 2013. 


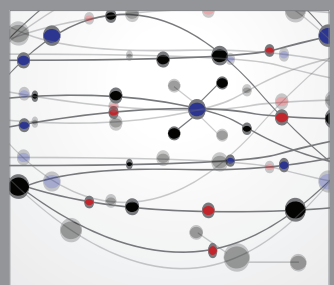

The Scientific World Journal
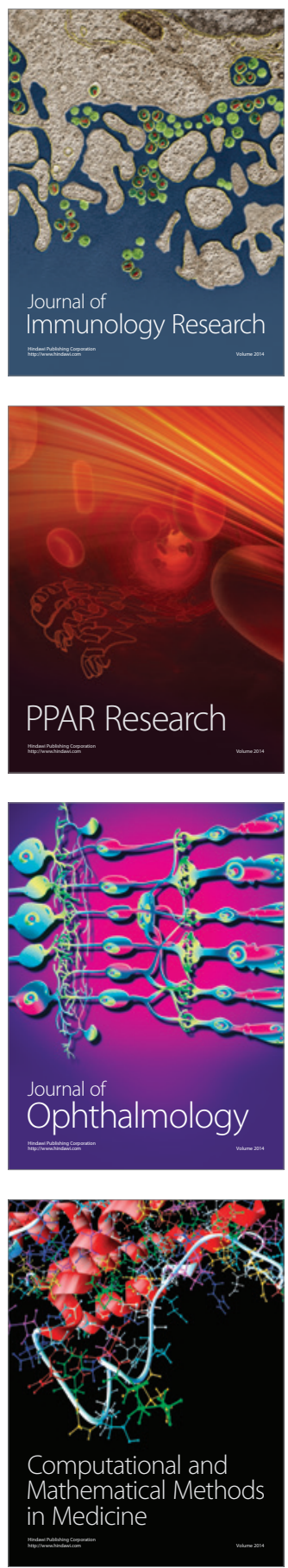

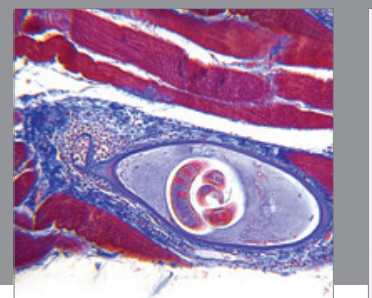

Gastroenterology

Research and Practice
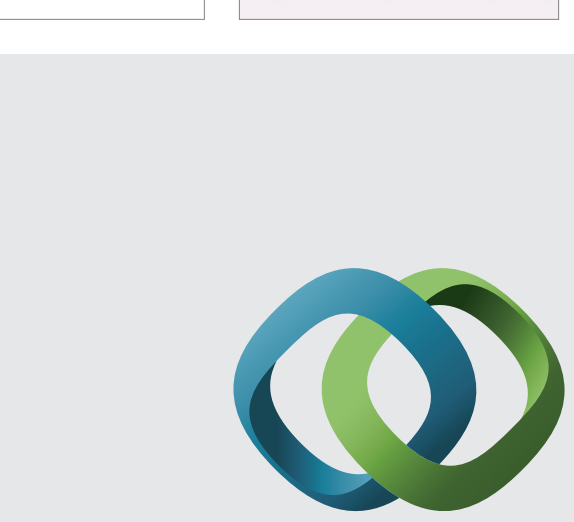

\section{Hindawi}

Submit your manuscripts at

http://www.hindawi.com
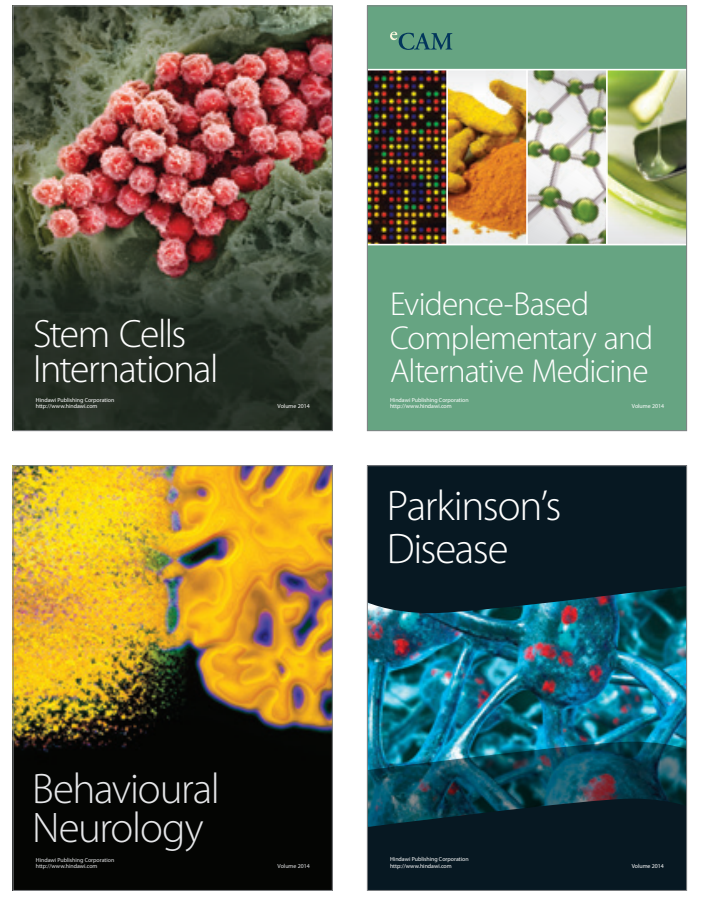
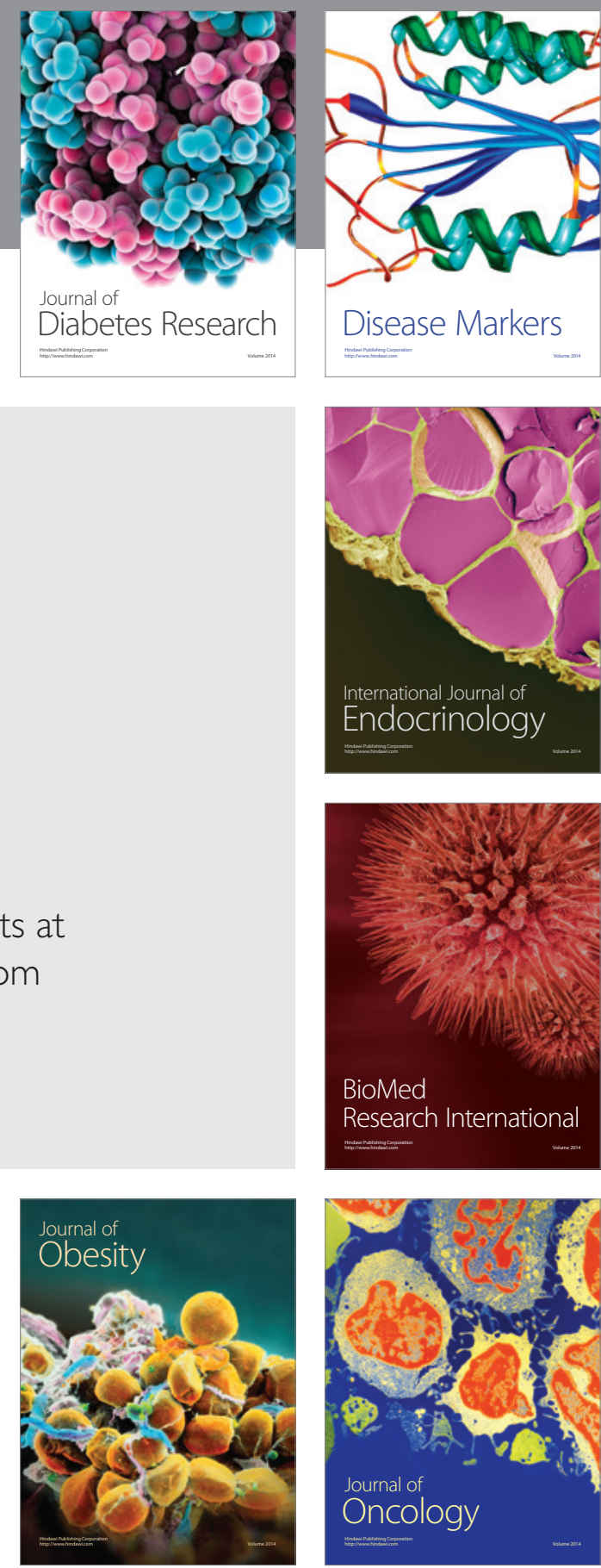

Disease Markers
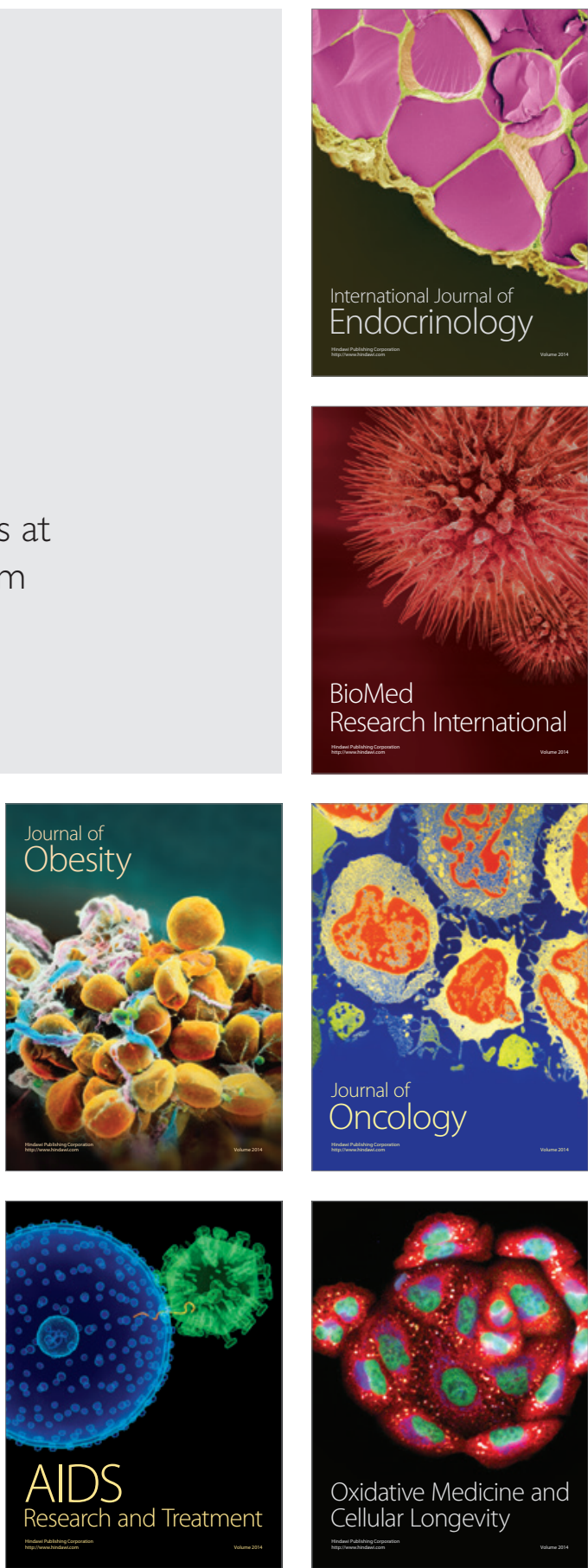